\title{
FUZZY APPROACH TO SUPPLY CHAIN MANAGEMENT FOR E-COMMERCE STORE
}

\author{
Original scientific paper
}

UDC:510.644:004.738.52

https://doi.org/10.18485/aeletters.2020.5.2.4

\author{
Djordje Dihovični ${ }^{1 *}$, Siniša Škrbić \\ ${ }^{1}$ The Academy of Technical Applied Sciences, Bulevar Zorana Djindjica 152a, Belgrade, Republic of Serbia \\ ${ }^{2}$ Faculty of Economics and Engineering Management in Novi Sad, University Business Academy in Novi Sad, \\ Cvećarska 2, 21000 Novi Sad, Serbia
}

\begin{abstract}
:
The model of e-commerce web store is developed and analyzed from supply chain management view of point. Main focus of this scientific paper is highlighted on fuzzy approach to crucial data about products, stored in the database of e-commerce web shop. For unit price of the product, and the probability of buying product of certain dimensions, it is calculated the fuzzy mean of the expected prize and the variance. The SWARA method is implemented and relative weight criteria is calculated in order to optimize supply chain management.
\end{abstract}

\author{
ARTICLE HISTORY \\ Received: 08.05.2020. \\ Accepted: 18.06 .2020 . \\ Available: 30.06.2020.
}

\section{KEYWORDS}

Fuzzy logic, web application, chain management, artificial intelligence

\section{INTRODUCTION}

Implementing a system of supply chain management is reduced to a series of steps to be applied in order to achieve the minimum cost of procurement and storage inventories. Adoption of a process or algorithm does not guarantee the implementation of this procedure, as well as the full realization of expected effects $[1,2]$.

Supply chain management requires coordination and information integration in order to reduce uncertainly in the demand through the complete network $[3,4]$.

The solid supply chain management should meet the customer demands, automate system testing, increase customer service, increase transparency into all operations through the Internet, optimize system giving more freedom to warehouse managers, leverage additional artificial intelligence capabilities and etc [5].

Developing well organized e-commerce chain management depends on sales strategies, customer services, and meeting customer wishes, such as fast purchase arrival, and low cost shipping.

Generally speaking about e-commerce chain management, it is obvious that it is not only connected with setting web site and selling products online. Despite the good infrastructure, logistics, and secure gateway it is crucial to make satisfied customers [6].

The most common way to pay online is through various types of payment cards. Some stores will not allow certain types of credit cards to make money transactions, other sites will have a lower tolerance threshold.

The financial part of the transaction can be done in real time and the e-shop can inform the customer that his / her credit card was declined before the customer left the site or the transaction can be done later after the customer confirms his order [7].

However, the good procedure involves the analyze of the sales process in e-commerce web store, and development of the real decision models [8], which might have a crucial role in making diagnostic conclusions about the states of the system $[9,10]$.

The e-shop can place the order with the manufacturer or distributor who sends the item directly to the customer via courier service. This 
avoids the need for sales facilities and warehouses, thus avoiding additional costs and saving time [11].

This paper proposes the fuzzy approach to supply chain management for e-commerce web store, and implementation of method of finding relative weight criteria.

\section{VIRTUAL STORE OF MACHINE ELEMENTS}

The Storefront model was developed for the virtual machine elements parts store. E-shops that use this model include electronic presentation of products, that describe and display products intended for sale [12].

Customers can search for a specific product or browse the e-catalog and browse the products on offer. The catalog contains a large number of different products, which is a great advantage over stores with limited space for goods.

As an added benefit, after ordering a particular product, the movement of our customers is tracked. It is common for customers to be notified by email of the time of their delivery, which is sent at the moment the delivery heads to their destination. The Storefront model allows manufacturers to sell their products on the Web 24 hours a day worldwide and includes [13,14]:

- online product catalog;

- purchase procedure;

- secure payment;

- manufacturer's server;

- manufacturer's database;

- provides a large selection of products and services;

- multiple orders in a single transaction.

The e-shop is composed of visual controls by which visitors manage the search, selection and purchase of goods and services. Some e-shop options can guide the customer and make the purchase easier. The option was set up, that displays the best-selling items, which is dynamically created by the software based on the data available in the e-shop database. The visual appearance of the storefront is customizable and independent of the pages controlled by the consumer basket software $[15,16]$.

The administrator application has the function of supporting the work of the user part of the presentation. The choice of the working environment of the administrator application depends on the manufacturer, and the application can be everything from a desktop application through a web application to a mobile application.
The administrator software connects to all ecommerce databases to update them [17].

The data important for the e-shop are:

- Product data;

- customer data;

- order data.

The products are cylindrical bearings of different dimensions.

All these data are entered into separate databases which are consisted of a different number of tables.

The main security problem is the transfer of personal data of users and their security after storage in the database. Data transfer is provided by using Secure Socket Layer (SSL) encryption, and database security is ensured by an administrative password.

The chosen solution to the hardware issue, is to set up a database and presentation for users on a web server while the administrative presentation is installed on the desktop system of the e-shop owner.

This e-commerce configuration reduces costs, because the costs include buying only one computer and renting a web server, which increases security against intrusion into the system.

There are also solutions in which the user presentation, administrative presentation and database are located on the computer of the estore and a solution in which each hardware item of the e-store, is located in a separate location, [18]. Each of these schedules has its advantages and disadvantages in terms of safety and cost.

An extremely important part of creating an eshop is designing its database. In this case, the term database means an organized set of data relating to products, user data and events related to the operation of the e-shop and software modules that allow access to this data, $[19,20]$.

During the creation of the presentation, a code layout might be chosen. Resolution is taken into account, and effects can be achieved with the help of CSS, Java script and flash animations. It should be taken care, that the content does not burden the customer, that it is not too colourful and intrusive, that there is not too much additional content that distracts the customer from the purchase.

The entire content of the page must fit in with each other and in that way it will form a visually appealing whole. This is achieved by initially selecting the basic concept of the page layout, and the chosen concept should be adhered during the creation of the entire presentation [21]. 


\section{DATABASE OF VIRTUAL STORE}

An extremely important part of creating an eshop is designing its database. Apart from creating the database, it is created stored procedures, triggers and functions necessary for retrieving useful data on the right time.

The tables of database refer to:

- Consumer basket- table Cart;

- Orders- table Orders;

- Products- table Products;

- Users- table Users.

The Cart table, is used to store user basket data. Each consumer basket received its own identification number in the table, column cart_ID, which is related to user identification- column cart_userID, product identification number column cart_productID and the quantity of ordered goods in the basket - column cart_quantity.

The Users table, stores the data that users enter via the database. The data in this table are used to identify the user, contact the user via e-mail or telephone, and send the purchased products to the customer's address, new user registration form and the account editing panel.

In the Products table, the data offered in the virtual mechanical parts shop are stored. A unique identification to each product is added, the price of the product is entered, the products are classified into certain categories, and described.

Using the presentation, the store administrator posses the ability to:

- manage site users;

- organize the site structure menu;

- add new pages and update existing site pages;

- organize product sharing or services (categories, subcategories, groups);

- manage product manufacturers;

- manage products: add new ones, edit existing ones, provide product details such as dimensions, weight and similar necessary data;

- manage product prices: purchase price, discount price, price supplements and sales price;

- E-mail which notifies customers of the status of the order.
By displaying the contents of the tables related to inventory, orders and customers, the complete database of the store and all its data were made available to the administrator of the presentation.

The e-shop is expected to provide the customer with easy access to the required data, an understandable system for ordering goods and services. The presentation should be entirely dedicated to the customer and allows him to make the desired purchase of goods or services in our eshop.

The user should be provided with easy navigation through the e-shop, easy product selection, quick and easy registration, easy overview of status and content baskets and update data in your user account.

An important part of the user presentation is the form for contacting the e-shop. Through it, the user is able to ask questions, give suggestions and comments to the owner / administrator of the eshop and thus solve any doubts or make suggestions for improving the work of e-shop.

The needs and scope of e-commerce products dictate to owners the choice of solutions. Solutions range from simple open source projects to a comprehensive ERP, Enterprise Resource Planning, of which only one part is the electronic consumer basket system.

Top-notch commercial solutions are available for purchase or rental as standalone programs or add-ons to an existing ERP system.

Such solutions are usually installed on the company's web server and can be integrated into an existing e-shop system so that ordering, payment, delivery, accounting and warehousing achieve a high degree of automation.

\section{FUZZY MEAN AND PAYTON SUPPORT}

The developed e-commerce system might be observed as fuzzy query system, with possibility to get the information from the database using quasi natural language sentences.

Despite the fact that there are different variations taking into account the particularities of different implementations, the fuzzy query sentence is consisted of records, by the degree of matching.

Our main product are cylindrical bearings various dimensions. In the Table 1 there are shown 
data from the Products table, for cylindrical

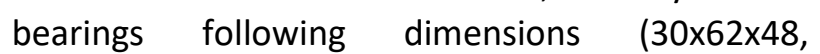
$35 \times 72 \times 52,40 \times 80 \times 56,45 \times 86 \times 58$ ), with unit price for more than 15 parts, and probability of selling the bearing type.

Table 1. Data from Products table

\begin{tabular}{|c|c|c|c|c|}
\hline Dimension & $30 \times 62 \times 48$ & $35 \times 72 \times 52$ & $40 \times 80 \times 56$ & $45 \times 85 \times 58$ \\
\hline $\begin{array}{c}\text { Unit Price } \\
\text { (EUR) }\end{array}$ & 34.72 & 43.53 & 50.76 & 39.66 \\
\hline $\begin{array}{c}\text { Probability } \\
\text { of selling } \\
\text { the bearing } \\
\text { type }\end{array}$ & 0.30 & 0.36 & 0.22 & 0.29 \\
\hline
\end{tabular}

The mean of the expected unit price could be obtained in the following way:

$34.72 \times 0.3+45.53 \times 0.36+50.76 \times 0.22+39.66 \times$ $0.29=49.47$

A variance of the expected unit prize is given with equation 2 :

$\left[(34.72-49.47)^{2} \times 0.3+(43.53-49.47)^{2} \times 0.36+\right.$ $\left.(50.76-49.47)^{2} \times 0.22+(39.66-49.47)^{2} \times 0.29\right] / 2=$ 49.51

In the next step it is assumed the degree of membership function for unit prices from the Table 2.

Table 2. Assumed membership function

\begin{tabular}{|c|c|c|c|c|}
\hline $\begin{array}{c}\text { Unit Price } \\
\text { (EUR) }\end{array}$ & 34.72 & 43.53 & 50.76 & 39.66 \\
\hline $\begin{array}{c}\text { Assumed } \\
\text { membership } \\
\text { function }\end{array}$ & 0.25 & 0.71 & 0.31 & 0.55 \\
\hline
\end{tabular}

The fuzzy set is presented down below:

$\{0.25 / 34.72,0.71 / 43.53,0.31 / 50.76,0.55 / 39.66\}$

The probability of fuzzy event is calculated as:

$0.25 \times 0.3+0.71 \times 0.36+0.31 \times 0.22+0.55 \times 0.29=$ 0.51

The fuzzy mean is obtained according to the procedure shown in the next equation:

$[(1 / 0.51) \times(34.72 \times 0.3 \times 0.25+43.53 \times 071 \times 0.36$ $+50.76 \times 0.31 \times 0.22+39.66 \times 0.29 \times 0.55] \times 2=$ 53.7
On the other hand, the Payton program is ideal for extracting some raw data and applying all necessary calculations.

For deeper and more sophisticated analyze, it is necessary to import into Python mathematical libraries, such as Numpy, Pandas and the others, and install Anaconda and Spider program.

The Table 2 created in Excel is saved in format CSV, which is useful for data manipulation.

By using Pandas Data Frame, the statistical properties might be calculated, as it is shown down below:

fom pandas import read_csv

from pandas import set_option

path = r"E:|Python|statdata.csv"

names $=$ ['cost', 'probability']

data $=$ read_csv(path, names=names)

set_option('display.width', 100)

set_option('precision', 2)

print(data.shape)

print(data.describe())

The statistical data after implementing pandas library, is presented:

unique price probability

count $\quad 4.00 \quad 4.00$

mean $\quad 42.17 \quad 0.29$

$\begin{array}{lll}\text { std } & 6.77 \quad 0.06\end{array}$

$\begin{array}{lll}\min & 34.72 & 0.22\end{array}$

$25 \% \quad 38.42 \quad 0.27$

$50 \% \quad 41.59 \quad 0.29$

$\begin{array}{lll}75 \% & 45.34 & 0.31\end{array}$

$\max \quad 50.76 \quad 0.36$

In this part of the paper it is presented fuzzy solution of the mean, by using assumed membership functions, and Python representation and machine learning approach with the raw data.

\section{SWARA METHOD}

In order to obtain relative weights of the mean criteria the SWARA method (Step-wise Weight Assestment Ratio Analysis) is applied.

In the following Table 3 it is presented average monthly income for cylindrical bearings of certain dimensions.

Table 3. Average monthly income for certain bearing types

\begin{tabular}{|c|c|c|c|c|}
\hline Dimension & $30 \times 62 \times 48$ & $35 \times 72 \times 52$ & $40 \times 80 \times 56$ & $45 \times 85 \times 58$ \\
\hline $\begin{array}{c}\text { Average } \\
\text { income } \\
\text { (EUR) }\end{array}$ & 1943.26 & 1545.27 & 2346.32 & 1982.47 \\
\hline
\end{tabular}


In Table 4 it has been shown the mean criteria for average monthly income for certain cylindrical bearing types, according to their expected significances, sorted in descending order.

For criteria it is chosen certain type of cylindrical bearings, taking into account specific dimension.

Table 4. The set criteria

\begin{tabular}{|c|c|}
\hline Criteria & Mean \\
\hline $40 \times 80 \times 56$ & 2346.32 \\
\hline $45 \times 85 \times 58$ & 1982.47 \\
\hline $30 \times 62 \times 48$ & 1943.26 \\
\hline $35 \times 72 \times 52$ & 1545.27 \\
\hline
\end{tabular}

The relative importance of the mean criteria $j$, to previous criteria (j-1), is given under Table 5 .

Table 5. The relative importance of the mean criteria

\begin{tabular}{|c|c|}
\hline Criteria & $\widetilde{S_{J}}$ \\
\hline $40 \times 80 \times 56$ & \\
\hline $45 \times 85 \times 58$ & 0.849 \\
\hline $30 \times 62 \times 48$ & 0.980 \\
\hline $35 \times 72 \times 52$ & 0.795 \\
\hline
\end{tabular}

The equation 1 , is used for solving coefficient $k_{j}$ as it is shown down below:

$$
\widetilde{k_{J}}=\left\{\begin{array}{cc}
\tilde{1} & j=1 \\
\widetilde{s_{J}}(+) \tilde{1} & j>1
\end{array}\right.
$$

Solving weight $\mathrm{q}$ is given with the equation 2 :

$$
\tilde{q_{J}}=\left\{\begin{array}{cc}
\tilde{1} & j=1 \\
\frac{\tilde{x}_{j-1}}{\widetilde{k_{J}}} & j>1
\end{array}\right.
$$

The relative weights of evaluation criteria is determined with the equation 3 :

$$
\widetilde{w_{J}}=\frac{\tilde{q}_{j}}{\sum_{k=1}^{n} \tilde{q}_{k}}
$$

The summary of the represented weight criteria, is given under Table 6:

Table 6. The relative importance of the mean criteria

\begin{tabular}{|c|c|c|c|c|}
\hline Criteria & $\widetilde{s_{J}}$ & $\widetilde{k_{J}}$ & $\tilde{q}_{j}$ & $\widetilde{w_{J}}$ \\
\hline $40 \times 80 \times 56$ & & 1 & 1 & 0.509 \\
\hline $45 \times 85 \times 58$ & 0.849 & 1.849 & 0.540 & 0.275 \\
\hline $30 \times 62 \times 48$ & 0.980 & 1.980 & 0.272 & 0.138 \\
\hline $35 \times 72 \times 52$ & 0.795 & 1.795 & 0.151 & 0.076 \\
\hline & & & 1.963 & 1.000 \\
\hline
\end{tabular}

The graphical representation of summary of resulting weight of criteria has been presented on Fig.1 in descending order.

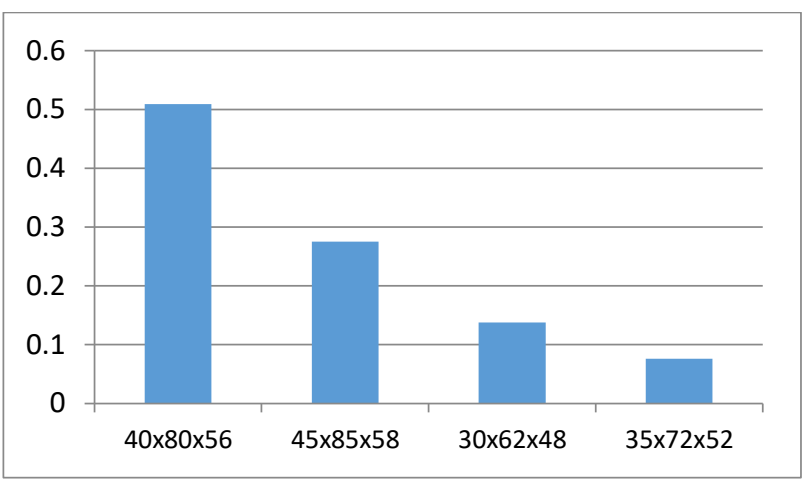

Fig.1. Graphical representation of resulting weight

\section{CONCLUSION}

In this study it is developed the supply chain management for virtual online store of cylindrical bearings of different dimensions. The main task of well performed supply chain management, is to persuade customers with a good offer and quality of services, and attached them to virtual store and permanently orient them in this way of shopping.

One part of the solution to this task is a good choice of visual solution and user presentation functions. The second part is the right choice of software solutions for the operation and administration of the virtual store, good database design, purchase of quality hardware and choice of configuration for setting up the user part, database and administrator part of the presentation.

It is applied fuzzy approach and for unit price of the product, it is calculated the fuzzy mean of the expected prize and the variance. The probability of fuzzy event is presented, as well as program support in Python programming language with imported mathematical libraries. After fuzzy analyze of the statistical data, the SWARA method is implemented in order of finding relative weights criteria. The results obtained by using proposed methods and techniques are valuable in order of building better supply chain management.

\section{REFERENCES}

[1] B. Bagchi, B. Chun Ha, T. Skjoett-Larsen, L. Boege Soerensen, Supply chain integration a European survey. The International Journal of Logistics Management, 16 (2), 2005: 275-294. https://doi.org/10.1108/09574090510634557 
[2] H. Gunter, G. Grote, O. Thees, Information technology in supply networks. Does it lead to better collaborative planning?. Journal of Enterprise Information Management, 19 (5), 2006: 540-550.

https://doi.org/10.1108/17410390610703666

[3] J. Woznica, K. Healy, O. Thees, The level of information systems integration in SMEs in Irish manufacturing sector. Journal of Small Business and Enterprise Development, 16 (1), 2009: 115-130.

https://doi.org/10.1108/14626000910932917

[4] E. Reusen, K. Stouthuysen, F. Roothoft, A. Van den Abbeele, $H$. Slabinnck, Imitation of Management Practices in Supply Networks: Relational and Environment Effects. Journal of Supply Chain Management, 56 (1), 2020: 5472.

https://doi.org/10.1111/jscm.12216

[5] R. Dichiara, Relationships between Small and Big Enterprises in Suppliers Networks: The Case of Mass Production Industry. ICSB 48th World Conference, Belfase, Vol.1, 2003: 211216.

[6] A. Muysinaliyev, S. Aktamov, Supply chain management concepts: literature review, IOSR Jornal of Business and Management, 15 (6), 2014: 60-66.

[7] Dj. Dihovicni, A. Ašonja, N. Radivojević, D. Cvijanović, S, Skrbić, Stability issues and program support for time delay systems in state over finite time interval. Physica $A$ : Statistical Mechanics and its Applications, 538, 2020: 122815.

https://doi.org/10.1016/j.physa.2019.122815

[8] A. Sharma, A. Goswami, D. Gupta, Fts-Sql: A query Language for Fuzzy Multidatabases. Proceedings of the World Congress on Engineering - (WCE 2009), Vol.1, 1-3 July, 2009, London U.K, pp.69-74.

[9] E. Desnica, A. Ašonja, D. Mikić, B. Stojanović, Reliability of model of bearing assembly on an agricultural of Cardan shaft, Journal of the Balkan Tribological Association, 21 (1), 2015: 38-48.

[10] A. Ašonja, E. Desnica, Reliability of Agriculture Universal Joint Shafts Based on Temperature Measuring in Universal Joint Bearing Assemblies. Spanish Journal of Agricultural Research, 13 (1), 2015: 1-8.

http://dx.doi.org/10.5424/sjar/2015131-6371

[11] M. Miletić, I. Miletić, Lean methodology and its derivates usage for production systems in modern industry. Applied Engineering Letters, 2 (4), 2017: 144-148.

[12] J.M. Merigo, K.J. Engemann, Fuzzy Decision Making with Probabilities and Induced Aggregation Operators. Computational Intelligence in Business and Economics, 3, 2010: 323-332.

https://doi.org/10.1142/9789814324441 0040

[13] A. Keropyan, A.M. Gil-Lafuente, (2010), Decision Making In Strategic Business Management. Computational Intelligence in Business and Economics, 3, 2010: 297-304.

https://doi.org/10.1142/9789814324441 0037

[14] J. Bergams, S. Gutnikov, V. Krasnoproshin, S, Popok, H. Vissia, Computer-Base Support to Decision-Making in Orthopaedics. International Conference on Intelligent Technologies in Human related Sciences, Vol.2, 5-7 July, 1996, Leon, Spain, pp.205-213.

[15] D. Perez Armayor, J.A. Díaz Batista, Decision Support Model for Information Systems Integration in Supply Chains: a Fuzzy Approach. Computational Intelligence in Business and Economics, 3, 2010: 281-288.

https://doi.org/10.1142/9789814324441 0035

[16] Dj. Dihovicni, Contructing knowledge database in stability of pneumatic pipelines. Tehnička dijagnostika, 14 (1), 2015: 7-14.

[17] J.R. Stock, S.L. Boyer, T. Harmon-Kitzer, Research Opportunities in Supply Chain Management. Journal of the Academy of Marketing Science, 38, 2010: 32-41.

https://doi.org/10.1007/s11747-009-0136-2

[18] S. Min, Z.G. Zacharia, C.D. Smith, Defining Supply Chain Management: In the Past, Present and Future. Journal of Business Logistics, 40 (1), 2019: 44-55.

https://doi.org/10.1111/jbl.12201

[19] Dj. Dihovicni, M. Medenica, Mathematical Modelling and Simulation of Pneumatic Systems. Advances in Computer Science and Engineering, Matthias Schmidt, IntechOpen, Chapter 9, 2011: 161-186.

https://doi.org/10.5772/15313

[20] R. Nicolas, Knowledge management impacts on decision making process. Journal of Knowledge Management, 8 (1), 2004: 20-31.

https://doi.org/10.1108/13673270410523880

[21] L. Xiuzhi, D. Yaping, Fault tolerant control for fixed set-point control nonlinear networked control systems. Technical Gazette, 23 (1) 2016: 35-41.

https://doi.org/10.17559/TV-20160108182240 